\title{
MODELING OF ADS-B DATA TRANSMISSION VIA SATELLITE
}

\author{
Volodymyr Kharchenko', Yuri Barabanov ${ }^{2}$, Andrii Grekhov ${ }^{3}$ \\ Air Navigation Systems Department of Air Navigation Institute of the National Aviation University \\ Kosmonavta Komarova ave. 1, 03680 Kiev, Ukraine \\ E-mails: ${ }^{1}$ ans@nau.edu.ua; ${ }^{2}$ brbnv@i.ua (corresponding author); ${ }^{3}$ grekhovam@ukr.net
}

Received 16 January 2013; accepted 03 September 2013

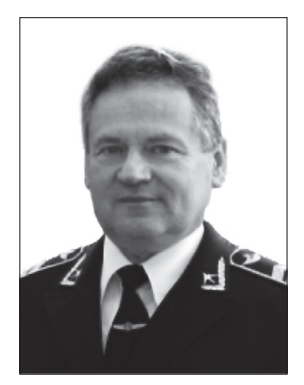

Volodymyr KHARCHENKO, $B S c, M S c$, PhD, Prof.

Date of birth: 1946.

Education: BSc, MSc (1962-1967) in Radio-Engineering at Radio Engineering Faculty of the Kiev Civil Aviation Engineers Institute.

Affiliations and functions: Engineer at United Aircraft troops (1967-1969). Junior and senior researcher (1969-1984), Assistant Professor (1984-1987), Dr Sci (Eng) (1994), Professor (19871994) of the Kiev International University of Civil Aviation. Since 2001 the Vice-Rector for Scientific-Research Work at the National Aviation University. Member of Ukrainian Transport Academy (1996), Russian Academy of Navigation and Control (1999), Institute of Engineers of Electrics and Electronics in the USA (2006).

Research interests: communication, navigation, surveillance.

Publications: author of about 400 scientific papers, monographs, textbooks, training aids, articles and proceedings.

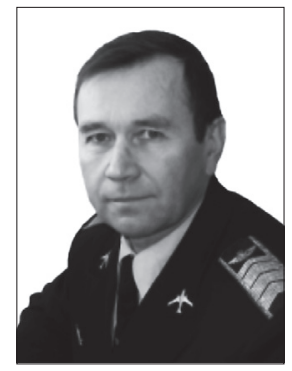

Yuri BARABANOV, $B S c, M S c, P h D$, Assoc. Prof.

Date of birth: 1951.

Education: BSc, MSc (1968-1973) in Aviation Radio Engineering Faculty of the Higher Military Engineering Aviation Academy in 1973 (Kiev), PhD (1993-1996) in the Kiev International University of Civil Aviation.

Affiliations and functions: served in the Army as an engineer, a teacher \& a researcher (1973-1998), Head of Satellite Communications Department of state enterprise Ukrkosmos (1998), senior engineer (1999-2003) in a company Ukrainian Satellite Communications (UkrSat), (2003 to present) Assistant Professor of the Department of Air Navigation System of the Institute of Air Navigation at National Aviation University (Kiev).

Research interests: computer modelling of antennas, wireless and satellite communications networks, telecommunications, ADS-B systems.

Publications: author of about 50 scientific papers, textbooks, training aids, and proceedings.

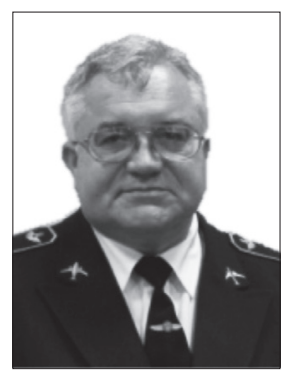

Andrii GREKHOV, $B S c, M S c, P h D$, Prof.

Date of birth: 1951.

Education: BSc, MSc (1968-1973) in Theoretical Physics at Physics Faculty and Commander of Radar Station at Military Department of the Kiev State T. Shevchenko University, PhD (19741980) in Institute of Semiconductors at Ukrainian Academy of Sciences, Doctor of Physical and Mathematical Sciences (1990) in Moscow Institute of Steel and Alloys, Professor (1990).

Affiliations and functions: junior researcher (1974-1980) in Institute of Semiconductors at Ukrainian Academy of Sciences; senior researcher in Institute of Physics at Ukrainian Academy of Sciences and Head of the Department of Mathematics and Physics in the Kiev Higher Antiaircraft Rocket Military Academy (1981-1990); Head of the Physics Department at National University of Food Technologies (1991-1996); diplomat and Acting Representative of Ukraine to ICAO (1997-2000); Vice-Rector for R\&D in Kiev European University (2001-2006); Director of ICAO Institute in National Aviation University; Professor at Air Navigation Systems Department (2006- to present). EUROCONTROL expert in ADS-B systems.

Research interests: surveillance, ADS-B systems, telecommunications, computer modelling. Publications: author of about 150 scientific papers, textbooks, training aids, and proceedings. 


\begin{abstract}
For modelling transmission of ADS-B messages via low-orbit satellite constellation Iridium, the original model of a communication channel "Aircraft-to-Satellite-to-Ground Station" was built using MATLAB Simulink. The model comprises "Aircraft Uplink Transmitter" (Bernoulli Random Binary Generator, Convolutional Encoder, BPSK Baseband Modulator, High Power Amplifier with a memoryless nonlinearity, Transmitter Dish Antenna Gain), "Uplink Path" (Free Space Path Loss, Phase/Frequency Offset), "Satellite Transponder" (Receiver Dish Antenna Gain, Satellite Receiver System Temperature, Complex Baseband Amplifier, Phase Noise, Transmitter Dish Antenna Gain), "Downlink Path" (Free Space Path Loss, Phase/Frequency Offset), "Ground Station Downlink Receiver" (Receiver Dish Antenna Gain, Ground Receiver System Temperature, Viterbi Decoder), "Error Rate Calculation" block and "Display". The modelling was realized without and with convolutional coding $(\mathrm{r}=3 / 4, \mathrm{~K}=7)$ at different noise temperatures and free space losses. Dependencies of a Bit Error Rate on free space path losses, antenna's diameter, phase/frequency offsets, satellite transponder linear gain, aircraft and satellite transponder high power amplifier back-off level, and phase noise were received and analysed.
\end{abstract}

Keywords: ADS-B, BER, communication channel, aircraft, satellite transponder, ground station, convolutional encoder, BPSK, free space loss, phase/frequency offset, memoryless nonlinearity, phase noise, Viterbi decoder, amplifier backoff level, noise temperature, antenna diameter.

\section{Introduction}

Flight safety depends on many elements (Kharchenko, Alexeiev 2010; Kulyk et al. 2011). Air-traffic control services in accordance with CNS/ATM (Communication, Navigation, and Surveillance/Air Traffic Management) concept should be enhanced with an ADS-B (Automatic Dependent Surveillance-Broadcast) function (Minimum ... 2002).

Global satellite communication service Iridium (Manual 2007) allows aviation users to send and receive voice, messaging and data regardless of their position on or above the earth: air-to-land, land-to-air and air-to-air.

On June 20, 2012 satellite Iridium operator has decided that from 2015 they will be putting ADS-B receivers on its next-generation satellite constellation, aimed at bringing global, real-time aircraft surveillance for air navigation service providers (ALAS... 2012). This new satellite system will enable continuous space-based monitoring and control of aircraft, using $1090 \mathrm{MHz}$ Extended Squitter ADS-B receivers built into each of the 66 satellites in Iridium's second-generation satellite constellation.

ADS-B is a surveillance technology for tracking aircraft as part of the Next Generation Air Transportation System (EUROCONTROL 2012). When using ADS-B system both pilots and controllers will see the same radar picture.

Telecommunication satellite systems are widely used in aviation due to advantages of satellite communication since it permits operation of many airplanes at long distances and provides independence of communication expenses on distances to airplanes (An Introduction ... 2009; Manual ... ; Roddy 2006; Woolner 2003).

The operation of satellite communication link is very sensitive to its parameters and even small alterations of these parameters may cause changing of data rate and ground coverage of a satellite system (Elbert 2003). For this reason, it is important to develop models of real satellite communication channels and investigate methods of correction of critical situations.
The Iridium system includes 66 low-orbit satellites at an altitude of $780 \mathrm{~km}$ and equally divided into 6 orbital planes (Iridium... 2008). Each satellite can communicate with the Airborne Earth Station. Each satellite uses three phased-array antennas for the user links. These arrays are designed to provide user-link service by communicating within the 1616-1626.5 MHz band. The gateway serves as a gateway to the Aviation Telecommunication Network for forwarding messages from an aircraft to the required Air Traffic Command or Aircraft Operational Communication unit.

Channels are implemented in the Iridium Satellite Network using a hybrid Time Division Multiple Access/ Frequency Division Multiple Access architecture based on Time Division Duplex using a 90 millisecond frame and a binary phase-shift keyed (BPSK) modulation scheme (or DE-QPSK differential encoding).

The aim of this paper is: 1) to design the model of communication channel "Aircraft-to-Satellite-toGround Station" with error-control coding for Iridium system using MATLAB Simulink software; 2) on the base of this model investigate the integrity of a channel and receive dependences of a bit-error rate (BER) on a free space path loss, a phase/frequency offset, a satellite transponder linear gain, airborne and backoff level of satellite transponder high power amplifiers, diameter of antennas, phase noise and noise temperature; 3 ) to analyse the constellation before and after high power amplifiers.

\section{A model for "Aircraft-to-Satellite-to-Ground Station" link}

A model for satellite communication channel "Aircraft - to-Satellite-to-Ground Station" without error-control coding was built earlier using MATLAB Simulink software and a demo model "RF Satellite Link" (Kharchenko 2012a, b). The original model, shown in figure 1, comprises "Aircraft Uplink Transmitter" (Bernoulli Random Binary Generator, Convolutional Encoder, BPSK Baseband Modulator, High Power Amp- 
lifier (HPA) with a memoryless nonlinearity, Transmitter Dish Antenna Gain), "Uplink Path" (Free Space Path Loss, Phase/Frequency Offset), "Satellite Transponder" (Receiver Dish Antenna Gain, Satellite Receiver System Temperature, Complex Baseband Amplifier, Phase Noise, Transmitter Dish Antenna Gain), "Downlink Path" (Free Space Path Loss, Phase/Frequency Offset), "Ground Station Downlink Receiver" (Receiver Dish Antenna Gain, Ground Receiver System Temperature, Viterbi Decoder), "Error Rate Calculation block" and "Display".

In the "Aircraft Uplink Transmitter" the Bernoulli Binary Generator block generates random binary numbers using a Bernoulli distribution with parameter pand produces "zero" with probability parameter $\mathrm{p}$ and "one" with probability $1-\mathrm{p}$ (the value $\mathrm{p}=0.5$ is used). The output signal is a frame-based matrix. The Bernoulli Binary Generator block generates a discrete signal and updates the signal at integer multiples of a fixed time interval, called the sample time. The length of this time interval has the value 1 . The output data type is "double".

Iridium system employs a BPSK modulation and forward error correction coding in the form of convolutional encoding with Viterbi decoding (Viterbi 1971). Iridium uses a rate $3 / 4$, constraint length $7,(r=3 / 4$; $\mathrm{K}=7$ ) convolutional code on both transmission and reception (Costello et al. 1998). The Convolutional Encoder block is using the poly2trellis ( $\left.7,\left[\begin{array}{ll}171 & 133\end{array}\right], 171\right)$ function with a constraint length of 7 , code generator polynomials of 171 and 133 (in octal numbers), and a feedback connection of 171 (in octal). The puncture vector is $[1 ; 1 ; 0 ; 1 ; 1 ; 0]$.

The BPSK Baseband Modulator block modulates a signal using the binary phase shift keying method. The output is a baseband representation of the modulated signal.

The High Power Amplifier block applies memoryless nonlinearity to complex baseband signal and provides five different methods for modelling the nonlinearity. In this paper results only for Saleh model with standard AM/AM and AM/PM parameters are discussed (Saleh 1981). A HPA backoff level is used to determine how close the satellite high power amplifier is driven to saturation. The following selected back-off is used to set the input and output gain of the Memoryless Nonlinearity block: $30 \mathrm{~dB}$ - the average input power is 30 decibels below the input power that causes amplifier saturation (in this case $\mathrm{AM} / \mathrm{AM}$ and $\mathrm{AM} / \mathrm{PM}$ conversion is negligible); $7 \mathrm{~dB}$ - moderate nonlinearity; and $1 \mathrm{~dB}$ - severe nonlinearity (see MATLAB demo model "RF Satellite Link").

The Transmitter (Receiver) Dish Antenna Gain block multiplies the input by a constant value (gain). Dependencies of a BER on the diameter of a transmit- ting and receiving antenna were obtained using vectors $\left[d_{1}, d_{2}\right]$ for each pair "transmitter-receiver". The first element in the vector $\left[d_{1}, d_{2}\right]$ represents the diameter (in meters) of a transmitting antenna and is used to calculate the gain in the Transmitter Dish Antenna Gain block. The second element represents the diameter of a receiving antenna and is used to calculate the gain in the Receiver Dish Antenna Gain block. The default setting is $[1.0,1.0]$ (antenna gain is 12,4) and diameters of all antennas (transmitting antenna on an aircraft, receiving and transmitting antennas on a satellite, receiving antenna on a ground station) were changed simultaneously.

In the "Uplink (Downlink) Path" the Free Space Path Loss block simulates the loss of signal power due to the distance between the aircraft uplink transmitter and the satellite transponder receiver. The block reduces the amplitude of the input signal by an amount that is determined by the Loss $(\mathrm{dB})$ parameter.

The Phase/Frequency Offset block applies phase and frequency offsets to an incoming signal.

In the "Satellite Transponder" the Satellite Receiver System Temperature block simulates the effects of thermal noise on a complex, baseband signal. Modelling was provided for two values of effective noise temperatures of $20 \mathrm{~K}$ (very low noise level) and $290 \mathrm{~K}$ (typical noise level) of satellite and ground station receiver systems. These settings were changed simultaneously and the last setting was used to view how typical receivers operate.

The Complex Baseband Amplifier block models an amplifier with noise (during simulations this setting was $0 \mathrm{~K})$. In addition to linear amplifier, this block has five different methods to model a nonlinear amplifier. In this paper results only for Saleh model with standard AM/ $\mathrm{AM}$ and AM/PM parameters are provided.

The Phase Noise block adds receiver phase noise to a complex baseband signal. The block applies the phase noise as follows: generates additive white Gaussian noise and filters it with a digital filter; adds the resulting noise to the angle component of the input signal. The level of the spectrum is specified by the noise power contained in a one hertz bandwidth offset from a carrier by a certain frequency. Modelling was provided for three levels: negligible (phase noise level: $-100 \mathrm{dBc} / \mathrm{Hz}$, frequency offset: $100 \mathrm{~Hz})$, low $(-55 \mathrm{dBc} / \mathrm{Hz}$, frequency offset: $100 \mathrm{~Hz})$ and high $(-48 \mathrm{dBc} / \mathrm{Hz}$, frequency offset: $100 \mathrm{~Hz})$.

In the "Ground Station Downlink Receiver" the Viterbi Decoder block decodes input symbols to produce binary output symbols. Non-quantised decision type parameter was used.

Comparing scatter plots of the signal after BPSK modulation and before demodulation allows viewing the impact of all impairments on the received signal. 


\section{Aeronautical satellite channel simulation}

For computer modelling a distance $780 \mathrm{~km}$ between the Iridium satellite and the ground station (satellite altitude) and an operational frequency of $1616 \mathrm{MHz}$ were chosen. Changing a carrier frequency of the link updates the Free Space Path Loss block (Fig 1).

Free-space path loss is the loss in signal strength that results from a line-of-sight path through free space, does not include the gain of the antennas used at the transmitter and receiver, is proportional to the square of the distance between the transmitter and receiver, and also proportional to the square of Iridium operational frequency. A dependence of a BER on free space path loss for different noise temperatures without coding and with convolutional coding is shown in figure 2. Loss values were changed simultaneously in uplink and downlink channels for equal diameter of antennas $\mathrm{d}_{1}=\mathrm{d}_{2}=$ $\mathrm{d}_{3}=\mathrm{d}_{4}=1.0 \mathrm{~m}$, moderate HPAs nonlinearity (back-off level $7 \mathrm{~dB}$ ) and satellite transponder gain - $0 \mathrm{~dB}$. Convolutional coding considerably decreases probability of er- rors and a BER is vanishing for free space path loss in the range from $0 \mathrm{~dB}$ to $161 \mathrm{~dB}$ (in case of very low noise temperature, $20 \mathrm{~K}$ ) and from $0 \mathrm{~dB}$ to $155 \mathrm{~dB}$ (in case of typical noise temperature, $290 \mathrm{~K}$ ). For low-orbital satellites such losses are realistic and for geostationary satellites they can achieve $200 \mathrm{~dB}$ (Osborne, Xie 1999; Sklar 2001).

Change of the diameter of all antennas has significant influence on probability of errors shown in figure 3 (the wider the diameter, the lower error probability). In this simulation, free space path loss was fixed (160 dB), nonlinearity of HPAs was moderate (back-off level $7 \mathrm{~dB}$ ), and two noise temperatures were considered (20 K and $290 \mathrm{~K})$.

Convolutional coding essentially reduces error probability that leads to a BER vanishing for antennas with a diameter of more than $1.2 \mathrm{~m}$. Iridium satellite has three Main Mission Antennas (each $0.86 \mathrm{~m}$ wide and $1.86 \mathrm{~m}$ high) (Iridium ... 2012). The same area has a circle with a diameter of $\approx 1.4 \mathrm{~m}$. Apparently, results of our modelling are in good consent with these data.

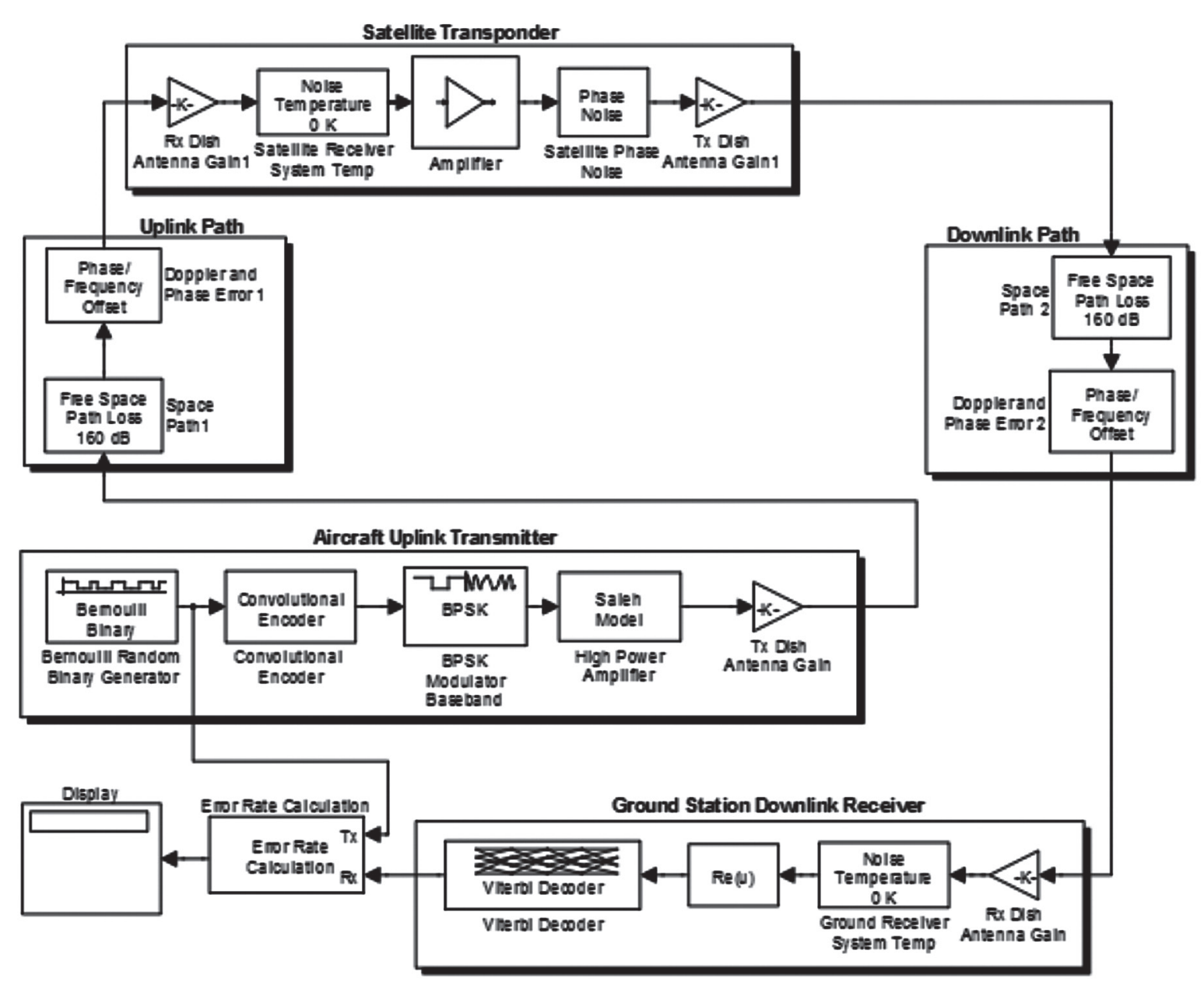

Fig. 1. Aircraft-to-Satellite-to-Ground Station Link 


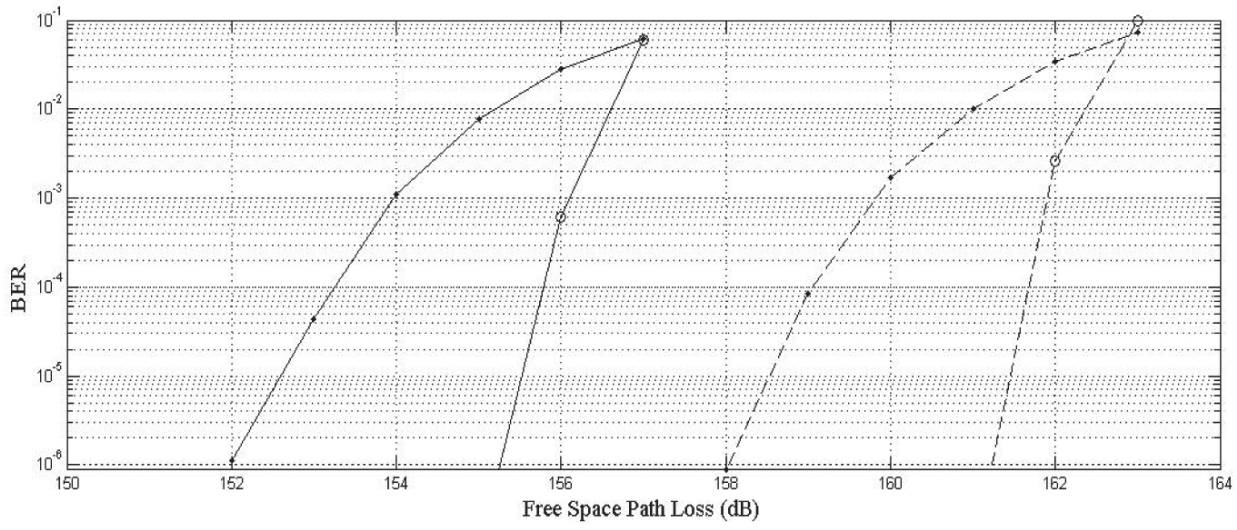

Fig. 2. Dependence of error probability for a BPSK modulation scheme on free space path loss in the uplink and the downlink: dots indicate values without coding, circles - with convolutional coding (rate $3 / 4$, constraint length $\mathrm{K}=7$ ); $20 \mathrm{~K}$ noise temperatures of satellite and ground receivers are indicated by dashed lines and $290 \mathrm{~K}$ by solid lines; HPAs back-off level is $7 \mathrm{~dB}$; phase and frequency offsets are equal to zero, $\mathrm{d}_{1}=\mathrm{d}_{2}=\mathrm{d}_{3}=\mathrm{d}_{4}=1.0 \mathrm{~m}$; satellite transponder phase noise is negligible

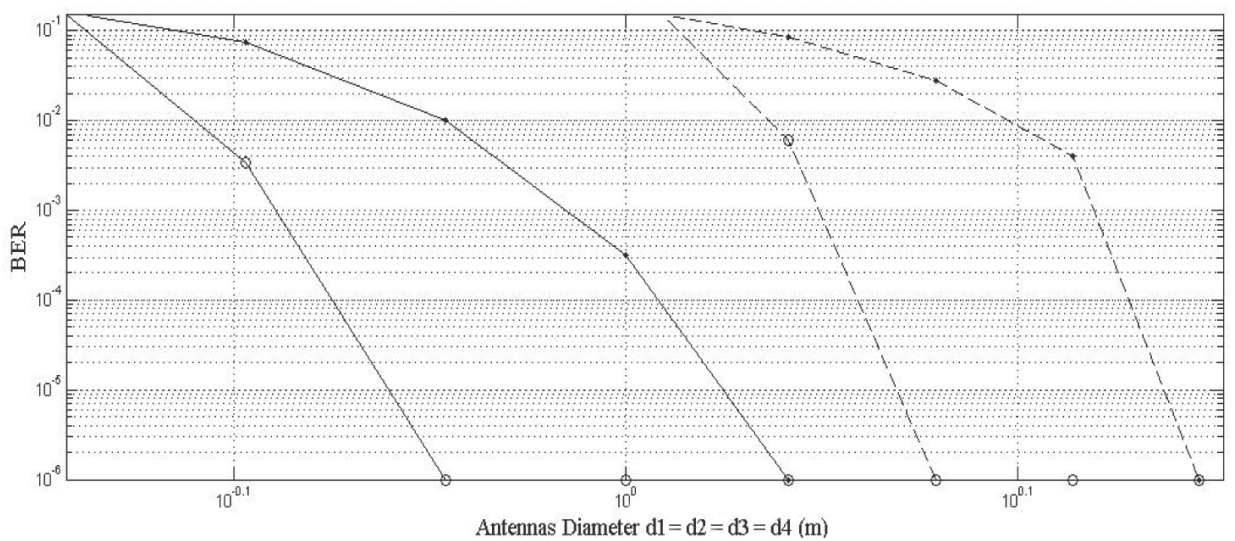

Fig. 3. Dependence of error probability for a BPSK modulation scheme on the diameter of satellite and aircraft antennas: dots indicate values without coding, circles - with convolutional coding (rate $3 / 4$, constraint length $\mathrm{K}=7$ ); $20 \mathrm{~K}$ noise temperatures of satellite and ground receivers are indicated by solid lines and $290 \mathrm{~K}$ by dashed lines; phase and frequency offsets are equal to zero; HPAs back-off level is $7 \mathrm{~dB}$, free space path loss is $160 \mathrm{~dB}$; satellite transponder phase noise is negligible

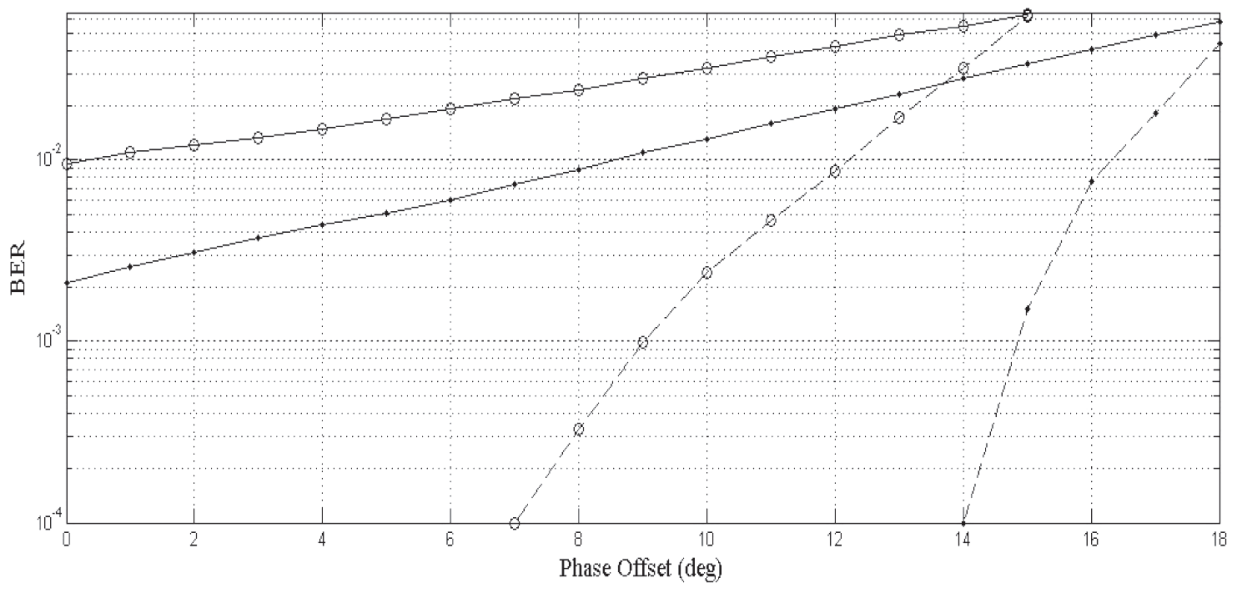

Fig. 4. Dependence of error probability for BPSK modulation scheme on phase offset in the uplink and the downlink: dots indicate values without coding, circles - with convolutional coding (rate $3 / 4$, constraint length $\mathrm{K}=7$ ); satellite and ground receivers noise temperatures is at $20 \mathrm{~K}$ (dots, free space path loss $162 \mathrm{~dB}$ ) and at $290 \mathrm{~K}$ (circles, free space path loss $157 \mathrm{~dB}$ ); HPAs backoff level amounts to $7 \mathrm{~dB}$; frequency offset is equal to zero; $\mathrm{d}_{1}=\mathrm{d}_{2}=\mathrm{d}_{3}=\mathrm{d}_{4}=1.0 \mathrm{~m}$; satellite transponder phase noise is negligible 
In the presence of an arbitrary phase offset introduced by the uplink and the downlink, the demodulator is unable to tell which constellation point is which. A dependence of a BER on phase offset in the uplink and the downlink is shown in figure 4 for two noise temperatures without convolutional coding and with it. With convolutional coding a BER is vanishing for phase shifts up to $7^{\circ}$ at uplink and downlink losses in free space of $157 \mathrm{~dB}$ and at a $290 \mathrm{~K}$ noise temperature of a satellite transponder and a ground receiver. Signal constellations for BPSK modulation scheme at the phase offset of $20^{\circ}$ in the uplink and the downlink are shown in figure 5 (distortions are caused by HPAs and phase offset), and the frequency offset in the uplink and the downlink at $2 \mathrm{~Hz}$ is provided in figure 6 (distortions are caused by HPAs).

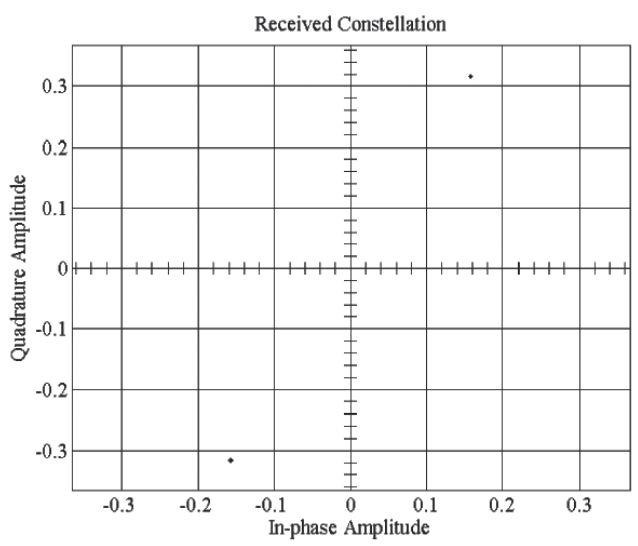

Fig. 5. End signal constellation for BPSK modulation scheme for phase offset $20^{\circ}$ in the uplink and the downlink: with convolutional coding (rate $3 / 4$, constraint length $K=7$ ); noise temperatures of satellite and ground receivers at $0 \mathrm{~K}$; free space path loss of $157 \mathrm{~dB}$; HPAs backoff level at $7 \mathrm{~dB}$; frequency offset is equal to zero; $\mathrm{d}_{1}=\mathrm{d}_{2}=\mathrm{d}_{3}=\mathrm{d}_{4}=1.0 \mathrm{~m}$; satellite transponder phase noise is negligible

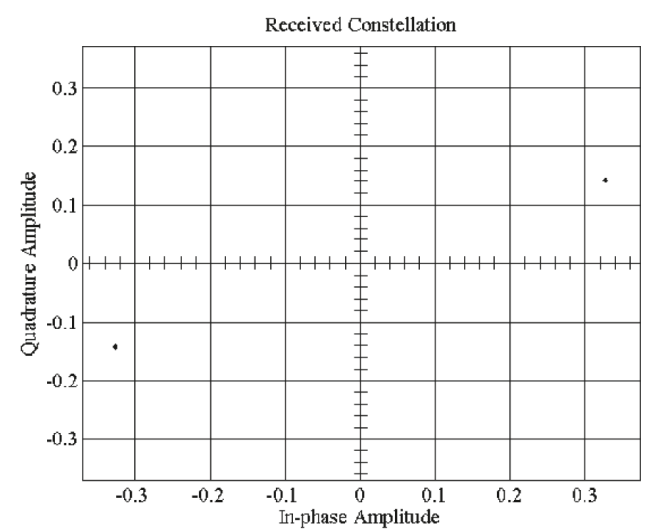

Fig. 6. End signal constellation for BPSK modulation scheme for frequency offset $2 \mathrm{~Hz}$ in the uplink and the downlink: with convolutional coding (rate $3 / 4$, constraint length $K=7$ ); satellite and ground receivers noise temperatures $0 \mathrm{~K}$; free space path loss $157 \mathrm{~dB}$; HPAs backoff level $7 \mathrm{~dB}$; phase offset is equal to zero; $d_{1}=d_{2}=d_{3}=d_{4}=1.0 \mathrm{~m}$; satellite transponder phase noise is negligible
Our model allows exploring the end-to-end simulation of "Aircraft-to-Satellite-to-Ground Station" communications links using an original model of a satellite transponder. The Complex Baseband Amplifier block can model a linear amplifier in which the linear method is implemented by a Gain block. A dependence of a BER on satellite transponder gain is shown in figure 7 for two noise temperatures without coding and with convolutional coding. Convolutional coding essentially reduces the error probability that leads to a BER vanishing for satellite amplifier linear gain of more than $8 \mathrm{~dB}$.

In the proposed model aircraft uplink transmitter amplifier and the satellite transponder are amplifying a signal on the uplink and the downlink sides of Iridium communications satellite according to the model of a travelling wave tube amplifier (TWTA) using the Saleh model. For an input sine curve of frequency $f$ and amplitude $r$, the TWTA is characterized by the following relationship (Elbert 2003):

$$
y(t)=A[r(t)] \sin (2 \pi f t+\phi[r(t)]),
$$

where the empirical relations:

$$
A(r)=\frac{a_{r} r}{1+b_{r} r^{2}}, \phi(r)=\frac{a_{\phi} r^{2}}{1+b_{\phi} r^{2}}
$$

describe $A(r)$ and $\phi(r)$. The first term is referred to as an $\mathrm{AM} / \mathrm{AM}$ conversion, and the second is an AM/PM conversion (the values of the four constants are as follows: $\left.a_{\downarrow r}=2.1587 ; b_{\downarrow r}=1.1517 ; a_{\downarrow} \phi=4.0330 ; b_{\downarrow} \phi=9.1040\right)$.

Nonlinear method options in the block apply a memoryless nonlinearity to the complex baseband input signal in the following manner: multiply the signal by a gain factor; split the complex signal into its magnitude and angle components; apply an AM/AM conversion to the magnitude of the signal, according to the Saleh nonlinearity method, to produce the magnitude of the output signal; apply an AM/PM conversion to the phase of the signal, according to the Saleh nonlinearity method, and add the result to the angle of the signal to produce the angle of the output signal; combine the new magnitude and angle components into a complex signal and multiply the result by a gain factor, which is controlled by the Linear gain parameter. A dependence of a BER on nonlinearities of satellite transponder and aircraft uplink transmitter amplifiers is shown in table.

Setting the Phase Noise parameter to a high level $(-48 \mathrm{dBc} / \mathrm{Hz}$, frequency offset at $100 \mathrm{~Hz})$ leads to the increased variance in the tangential direction in the received signal scatter plot shown in figure 8 . Setting the Phase Noise to a low level $(-55 \mathrm{dBc} / \mathrm{Hz}$, frequency offset at $100 \mathrm{~Hz}$ ) leads to a situation when the variance in the tangential direction has slightly decreased. This level of phase noise is not sufficient to cause errors. 


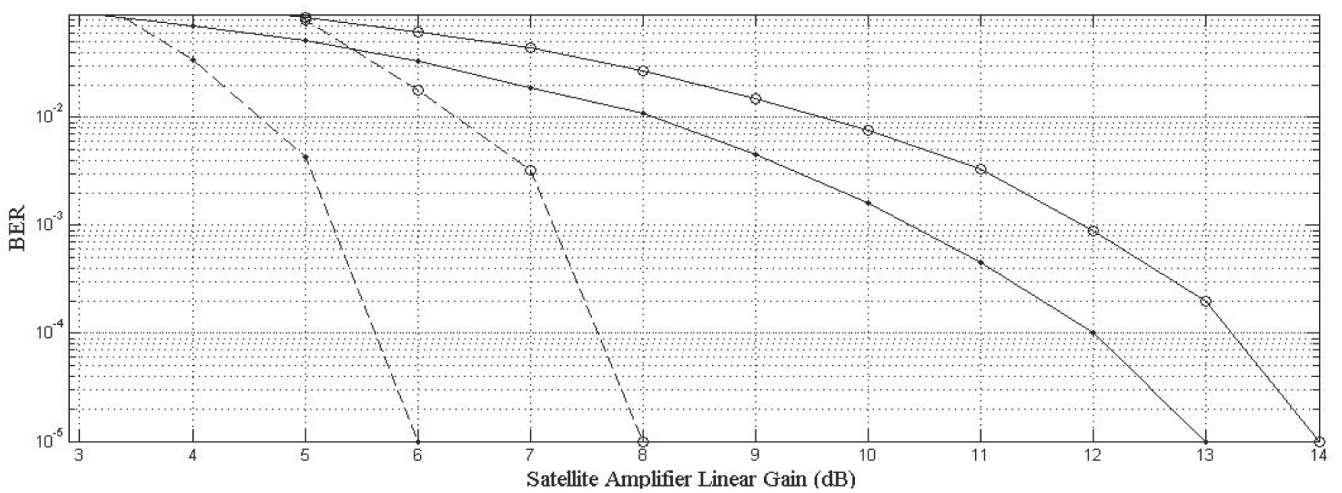

Fig. 7. Dependence of error probability for BPSK modulation scheme on satellite transponder linear gain: dots indicate values without coding, circles - with convolutional coding (rate 3/4, constraint length $\mathrm{K}=7$ ); satellite and ground receivers noise temperatures is at $20 \mathrm{~K}$ (dots, free space path loss $162 \mathrm{~dB}$ ) and at $290 \mathrm{~K}$ (circles, free space path loss $157 \mathrm{~dB}$ ); phase and frequency offsets are equal to zero; HPAs nonlinearity is negligible; $\mathrm{d}_{1}=\mathrm{d}_{2}=\mathrm{d}_{3}=\mathrm{d}_{4}=1.0 \mathrm{~m}$; satellite transponder phase noise is negligible

Table. Dependence of Error Probability for BPSK Modulation Scheme on Amplifiers Nonlinearity

\begin{tabular}{|c|c|c|c|c|c|c|}
\hline \multirow[t]{3}{*}{$\begin{array}{l}\text { HPA back-off level } \\
\text { (Aircraft and Satellite) }\end{array}$} & \multicolumn{3}{|c|}{$\begin{array}{c}\text { BER (Satellite and Ground Receiver } \\
\text { Noise Temperatures } \mathrm{T}=20 \mathrm{~K} \text { ) }\end{array}$} & \multicolumn{3}{|c|}{$\begin{array}{l}\text { BER (Satellite and Ground Receiver } \\
\text { Noise Temperatures } \mathrm{T}=290 \mathrm{~K} \text { ) }\end{array}$} \\
\hline & \multicolumn{3}{|c|}{ Free Space Path Loss } & \multicolumn{3}{|c|}{ Free Space Path Loss } \\
\hline & $107 \mathrm{~dB}$ & $116 \mathrm{~dB}$ & $120 \mathrm{~dB}$ & $110 \mathrm{~dB}$ & $112 \mathrm{~dB}$ & $115 \mathrm{~dB}$ \\
\hline $\begin{array}{l}\text { 1. Aircraft HPA }-30 \mathrm{~dB} \\
\text { Satellite HPA }-30 \mathrm{~dB}\end{array}$ & 0.0 & 0.0 & 0.0 & 0.0 & 0.0 & 0.0 \\
\hline $\begin{array}{l}\text { 2. Aircraft HPA }-7 \mathrm{~dB} \\
\text { Satellite HPA - } 30 \mathrm{~dB}\end{array}$ & 0.0 & 0.0 & $1.7 \cdot 10^{-3}$ & 0.0 & 0.0 & $4.8 \cdot 10^{-2}$ \\
\hline $\begin{array}{l}\text { 3. Aircraft HPA }-1 \mathrm{~dB} \\
\text { Satellite HPA - } 30 \mathrm{~dB}\end{array}$ & 0.0 & $2.3 \cdot 10^{-2}$ & $4.9 \cdot 10^{-1}$ & $8.3 \cdot 10^{-3}$ & $4.4 \cdot 10^{-1}$ & $5.0 \cdot 10^{-1}$ \\
\hline $\begin{array}{l}\text { 4. Aircraft HPA }-30 \mathrm{~dB} \\
\text { Satellite HPA }-7 \mathrm{~dB}\end{array}$ & 0.0 & 0.0 & 0.0 & 0.0 & 0.0 & 0.0 \\
\hline $\begin{array}{l}\text { 5. Aircraft HPA }-7 \mathrm{~dB} \\
\text { Satellite HPA }-7 \mathrm{~dB}\end{array}$ & 0.0 & 0.0 & $1.7 \cdot 10^{-3}$ & 0.0 & 0.0 & $4.8 \cdot 10^{-2}$ \\
\hline $\begin{array}{l}\text { 6. Aircraft HPA }-1 \mathrm{~dB} \\
\text { Satellite HPA }-7 \mathrm{~dB}\end{array}$ & 0.0 & $2.3 \cdot 10^{-2}$ & $4.9 \cdot 10^{-1}$ & 0.0 & $4.4 \cdot 10^{-1}$ & $5.0 \cdot 10^{-1}$ \\
\hline $\begin{array}{l}\text { 7. Aircraft HPA }-30 \mathrm{~dB} \\
\text { Satellite HPA }-1 \mathrm{~dB}\end{array}$ & 0.0 & 0.0 & 0.0 & 0.0 & 0.0 & 0.0 \\
\hline $\begin{array}{l}\text { 8. Aircraft HPA }-7 \mathrm{~dB} \\
\text { Satellite HPA }-1 \mathrm{~dB}\end{array}$ & 0.0 & 0.0 & $1.7 \cdot 10^{-3}$ & 0.0 & 0.0 & $4.8 \cdot 10^{-2}$ \\
\hline $\begin{array}{l}\text { 9. Aircraft HPA }-1 \mathrm{~dB} \\
\text { Satellite HPA }-1 \mathrm{~dB}\end{array}$ & 0.0 & $2.3 \cdot 10^{-2}$ & $4.9 \cdot 10^{-1}$ & $8.3 \cdot 10^{-3}$ & $4.4 \cdot 10^{-1}$ & $5.0 \cdot 10^{-1}$ \\
\hline
\end{tabular}

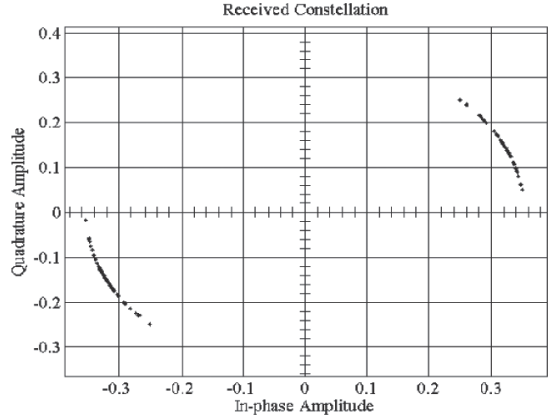

Fig. 8. Signal constellation for BPSK modulation scheme for a high level of phase noise $(-48 \mathrm{dBc} / \mathrm{Hz}$, frequency offset at $100 \mathrm{~Hz}$ ): with convolutional coding (rate $3 / 4$, constraint length $\mathrm{K}=7$ ); satellite and ground receivers noise temperatures at $0 \mathrm{~K}$; free space path loss $157 \mathrm{~dB}$; HPAs backoff level $7 \mathrm{~dB}$; phase offset is equal to zero; $\mathrm{d}_{1}=\mathrm{d}_{2}=\mathrm{d}_{3}=\mathrm{d}_{4}=1.0 \mathrm{~m}$

\section{Conclusions}

For modelling ADS-B message transmission on the base of low-orbit satellite constellation Iridium, the original model of a communication channel "Aircraft-to-Satellite-to-Ground Station" with error-control coding was built using MATLAB Simulink software.

For the study of a signal transmission through a communication channel without coding and with convolutional coding the following parameters were changed: losses in a free space simultaneously in the uplink and the downlink from $0 \mathrm{~dB}$ to $250 \mathrm{~dB}$ in each channel (Fig. 2); noise temperature of a satellite transponder and a ground receiver (20 K, $290 \mathrm{~K})$; symmetrical and asymmetrical diameters of all four antennas that increased or reduced the power of the received signal (Fig. 3); phase 
and frequency (due to Doppler's effect) offsets simultaneously in the uplink and the downlink from $0^{\circ}$ to $20^{\circ}$ (from $0 \mathrm{~Hz}$ to $10 \mathrm{~Hz}$ ) in each channel (Figs 4-6); satellite transponder linear gain from $0 \mathrm{~dB}$ to $15 \mathrm{~dB}$ (Fig. 7); nonlinearity of HPAs on an airplane and a satellite (Tab.); and satellite transponder phase noise (Fig. 8).

Signal changes were analysed by means of active windows-indicators which allowed defining a BER and constellations of the transmitted and received signals (Figs 5, 6).

Dependencies shown in figures $2-8$ were obtained for "standard parameters": without coding and with convolution coding (rate $3 / 4$, constraint length $K=7$ ); noise temperatures satellite and ground receivers at $20 \mathrm{~K}$ and $290 \mathrm{~K}$; without phase and frequency offsets; negligible HPAs; $\mathrm{d}_{1}=\mathrm{d}_{2}=\mathrm{d}_{3}=\mathrm{d}_{4}=1.0 \mathrm{~m}$; negligible satellite transponder phase noise. Values of free space path losses phase and frequency offsets, diameter of antennas were specified in each separate case.

For "standard parameters" a BER is vanishing for free space path losses changing from $0 \mathrm{~dB}$ to $163 \mathrm{~dB}$ with use of convolution coding and a noise temperature of $20 \mathrm{~K}$.

Diameters of antennas essentially influence a BER, which is shown in (Fig. 3). The probability of errors for "standard parameters" is vanishing for diameters of all antennas of more than $1.2 \mathrm{~m}$. This result is in good agreement with the size of Iridium satellite antennas (Iridium... 2008). At the same time, calculations with a diameter of aircraft transmitting antenna $\mathrm{d}_{1}=0.3 \mathrm{~m}$, a diameter of satellite receiving antenna $\mathrm{d}_{2}=1 \mathrm{~m}$, a diameter of satellite transmitting antenna $d_{3}=1 \mathrm{~m}$ and a diameter of ground station receiving antenna $d_{4}=2 \mathrm{~m}$ (for the noise temperature $0 \mathrm{~K}$ ) results in BER vanishing for losses in free space up to $220 \mathrm{~dB}$. This result is in good agreement with a satellite communication channel budget (Sklar 2001).

The influence of convolution coding on dependence of a BER on phase offsets in the uplink and the downlink is critical and changes the character of this dependence (Fig. 4) by essentially reducing a level of errors. Under "standard parameters" and noise temperature of $20 \mathrm{~K}$, a BER is vanishing at phase shifts up to $14^{\circ}$. The signal constellation (Fig. 5) shows a presence of strong distortions during signal transmission. Frequency offsets caused by the Doppler's effect (Fig. 6) also cause essential distortions.

The satellite transponder is the central element of a considered communication channel, and transponder linear gain along with a choice of a working point (level of TWTA nonlinearity) have a strong impact on quantity of errors at data transmission. Under "standard parameters", noise temperature at $290 \mathrm{~K}$ and free space losses at $157 \mathrm{~dB}$ in the uplink and $157 \mathrm{~dB}$ in the downlink a BER vanishes when transponder linear gain is at least $8 \mathrm{~dB}$
(Fig. 7). At a noise temperature of $20 \mathrm{~K}$ and free space losses at $160 \mathrm{~dB}$ in the uplink and $160 \mathrm{~dB}$ in the downlink a BER vanishes when transponder linear gain is at least $6 \mathrm{~dB}$.

The influence of HPA back-off parameter on a BER was studied for different free space losses and noise temperatures (Tab.). In this case, a gain of all four antennas was equal to the unit in order to exclude effect of pre-amplifying in front of satellite transponder HPA. Nevertheless, results of modelling have revealed that the back-off parameter of the aircraft has a defining influence on a BER (compare cases 2, 5, 8 and 3, 6, 9 in the table). It is possible to explain this by entering pre-distortions by aircraft HPA, which then are partially compensated by transponder HPA.

The impact of phase noise on a transmitted signal is illustrated in figure 8.

The proposed model can be used as a basic model for investigation of communication between two airplanes and ground stations using several satellites.

The developed model can also be used for finding optimal methods of error-correcting coding.

\section{References}

ALAS ADS-B technologies [online]. 2012 [cited 10 January 2013]. Available from Internet: http://adsbsat.com/spacebased-ads-b/what-is-alas

An Introduction to Aircraft Satellite Tracking [online]. 2009 [cited 10 January 2013]. Available from Internet: http://www.indigosat.com/marketing/About satellite tracking.pdf/

Costello, D. J.; Hagenauer, J.; Imai, H.; Wicker, S. B. 1998. Applications of error-control coding, IEEE Transactions on Information Theory 44(6): 2531-2560.

http://dx.doi.org/10.1109/18.720548

Elbert, B.; Elanix, M. 2003. Simulating the Performance of Communication Links with Satellite Transponders [online]. Available from Internet: http:// www. applicationstrategy. com/Communications_simulation.htm

EUROCONTROL [online]. 2012. ADS-B Sites [cited 10 January 2013]. Available from Internet: http:// www.eurocontrol.int/ads_b_sites/, http:// www. eurocontrol.int/ surveillance/cascade

Iridium-Adds-ADS-B-to-its-Iridium-NEXT-Constellation [online]. 2012 [cited 10 January 2013]. Available from Internet: http://www.aviationtoday.com/the-checklist/76558. html

Iridium Satellites [online]. 2008 [cited 10 January 2013]. Available from Internet: http://www.highspeedsat.com/ iridium-satellite.php

Kharchenko, V. P.; Alexeiev, O. P. 2010. Interpretation of neural network technologies for prediction and management of risk factors, Aviation 14(1): 19-23. http://dx.doi. org/10.3846/aviation.2010.03

Kharchenko, V. P.; Barabanov, Y. M.; Grekhov, A. M. 2012a. Modeling of aviation telecommunications, Proceedings of the National Aviation University (1): 5-13.

Kharchenko, V. P.; Barabanov, Y. M.; Grekhov, A. M. 2012b. Modelling of satellite channel for transmission of ADS-B messages, Proceedings of the National Aviation University (3): 9-14. 
Kulyk, M. S.; Kharchenko, V. P.; Matiychyk, M. P. 2011. Justification of thrust vector deflection of twin-engine unmanned aerial vehicle power plants, Aviation 15(1): 25-29. http://dx.doi.org/10.3846/16487788.2011.566319

Manual for ICAO Aeronautical Mobile Satellite (Route) Service Part 2-iridium Draft V4.0 [online]. 2007. 77 p. [cited 10 January 2013]. Available from Internet: http: //legacy.icao. int/ anb/panels/acp/wg/m /iridium_swg/

Manual on Detailed Technical Specifications for the Aeronautical Telecommunication Network (ATN), Doc. 9880-AN/466.

Minimum Aviation System Performance Standards for Automatic Dependent Surveillance-Broadcast (ADS-B). RTCA, Inc. 2002. DO-242A.

Osborne, W. P.; Xie, Y. 1999. Propagation Characterization of LEO/MEO Satellite Systems at 900-2100 MHz. Emerging Technologies Symposium Wireless Communications and Systems, 21.1-21.8. IEEE Conference Proceedings [online], [cited 10 January 2013]. Available from Internet: http:// opensiuc.lib.siu.edu/ece_confs/52

Roddy, D. 2006. Satellite Communications. 4th ed. The McGraw Hill Companies, Inc. 656 p.

Saleh, A. A. M. 1981. Frequency-independent and frequency-dependent nonlinear models of TWT amplifiers, IEEE Transactions on Communications 29(11): 1715-1720. http://dx.doi.org/10.1109/TCOM.1981.1094911

Sklar, B. 2001. Digital Communications. Prentice Hall PTR. $953 \mathrm{p}$.

Viterbi, A. 1971. Convolutional codes and their performance in communications systems, IEEE Transactions on Communications, Communication Technology 19(5): 751-772.

Woolner, P. 2003. Aircraft-to-satellite Links Suitable for Transmitting USDA Forest Service Infrared Forest Fire Data [online], [cited 10 January 2013]. Available from Internet: http:// nirops.fs.fed.us /docs/upload/ USFS_satcom_report.pdf 